UDC 57.084-089.6:615.018.82.013.014.41

Sukach A. N., Lebedinsky A. S., Ochenashko O. V., Petrenko A. Yu.

Institute for Problems of Cryobiology and Cryomedicine of the National Academy of Sciences of Ukraine, Kharkiv, Ukraine

e-mail: an_sukach@ukr.net

\title{
TRANSPLANTATION OF CRYOPRESERVED RAT FETAL NEURAL CELLS IN SUSPENSION AND IN MULTICELLULAR AGGREGATES INTO RATS WITH SPINAL CORD INJURY
}

\section{ABSTRACT}

Today cell transplantation is one of the promising approaches of spinal cord injuries treatment. The aim of the work was to study the effect of cryopreserved fetal neural cell transplantation in suspensions and cell aggregates for motor activity recovery of rats with experimental spinal cord injury.

MATERIALS AND METHODS. Cells were isolated from the brain tissue of rat fetuses 15-16 days of gestation. The formation of aggregates was performed during short-term cultivation at a concentration of $8 \cdot 10^{6} \mathrm{cell} / \mathrm{s} / \mathrm{mL}$ in medium with $10 \%$ adult rat serum. Cell transplantation was performed into the damaged area of spinal cord in aggregates or suspension. To fix transplanted cells in the damaged area we used alginate gel.

RESULTS. Transplantation of cryopreserved fetal neural cells in alginate gel had the positive effect on dynamics of rats' motor activity recovery. That was manifested in the extensive mobility of three joints of one limb and the limited mobility of two joints of the other with simultaneous recovery of the sensitivity of the hind limbs.

CONCLUSION. Cryopreserved fetal neural cells aggregates had a high therapeutic potential on rat traumatic spinal cord injury compared with cell suspension by improving the structure of forming nervous tissue and significantly increasing the rate of hind limb function recovery.

KEYWORDS: neural cell culture, cryopreservation of cells, spinal cord injury, cell transplantation

Nowadays there is no efficient methods of treatment for spinal cord injuries. It is due to the lack of methods of neurons regeneration and recovery of damaged spinal cord structure. Cell therapy is one of the promising methods. However the positive experience in the application of stem cells for the treatment of traumatic spinal cord injury is minimal. This is due both to the low level of their survival, because of the unfavorable microenvironment, and with not quite clear mechanisms for their integration into the damaged spinal cord tissue. These problems are also common with a question of determining the optimal source of cells [1] and the choice of optimal methods of cells' transplantation, which will contribute to their survival and restoration of the damaged spinal cord tissue cytoarchitectonics.

Currently, there are certain hopes to use three-dimensional cell systems in cell therapy [2-4]. As such systems, used for the treatment of spinal cord injuries, can serve multicellular aggregates, formed by isolated neural cells (NCs). It was shown that in multicellular aggregates conditions, necessary for survival and effective functioning of neural stem/progenitor cells, are created [5-7].
Widespread applying of stem cells in cell therapy of spinal cord injuries is also impossible without the creation of the available supply of cells, which requires the development of methods for their long-term storage, the most preferred of which is cryopreservation.

Thus, the aim of the study was to investigate the effect of transplantation of cryopreserved aggregates of rat fetal NCs on the recovery of motor activity of rat hind limbs with experimental spinal cord injury.

\section{MATERIALS AND METHODS}

Newborn white outbred rats from experimental clinic of Institute for Problems of Cryobiology and Cryomedicine NAS of Ukraine have been used in studies. The work with animals was carried out in accordance with the «General principles of animal experiments», approved by $\mathrm{V}$ National Congress on Bioethics (Kyiv, 2013), consistent with the provision of «IV European Convention for the Protection of Vertebrate Animals used for 
experimental and other scientific purposes» (ETS 123, Strasbourg, 1986) and resolution of the Committee on Bioethics of the Institute for Problems of Cryobiology and Cryomedicine.

Neural cells were isolated from the brain tissue of rat fetuses 15$16^{\text {th }}$ days of gestation. The first day of pregnancy was considered the identification of sperm in vaginal smears after rat coupling. For this purpose, the brain was removed from the skull, washed with sterile DMEM/ F12 medium (Sigma, USA) and then placed in $0.25 \%$ trypsin solution and incubated at $37^{\circ} \mathrm{C}$ for 5 minutes. Thereafter, tissue was transferred to DMEM/F12 medium supplemented with $10 \%$ adult rat serum (ARS) and mechanically disaggregated into single cells using vibration [8]. The suspension was passed through a sterile filter of blood transfusion system (Plastimed, Ukraine). Then the cells were washed by centrifugation at $150 \mathrm{xg}$ for 5 minutes. The resulting cell pellet was suspended in DMEM/ F12 medium supplemented with $0.6 \%$ glucose, $2 \mathrm{mM}$ glutamine, $3 \mathrm{mM}$ sodium bicarbonate with $10 \%$ ARS.

For aggregates formation NCs were plated in 24-well plastic plate (Corning, USA) at a concentration of $4 \cdot 10^{6}$ cells per well and cultured for 2 hours in $0.5 \mathrm{~mL}$ supplemented DMEM/F12 with $10 \%$ ARS [9]. Cells were resuspended with a pipette every 15 minutes.

Cell staining with $0.4 \%$ trypan blue solution was used as an express method of viability determining. NCs viability and count was performed in Goriaev's chamber. Determination of NCs viability from aggregates was carried out after their disaggregation into single cells suspension by pipetting.

Cryopreservation of suspensions and multicellular NCs aggregates was carried out in polycarbonate freezing container Nalgene Mr. Frosty (Sigma-Aldrich, USA) at $1{ }^{\circ} \mathrm{C} / \mathrm{min}$ to $-80^{\circ} \mathrm{C}$ in cryocontainers (Corning, USA) under the protection of $10 \%$ DMSO in DMEM/F12 medium (Sigma, USA) at the presence of $10 \%$ ARS. Thus, the final concentration of the cells in the suspension was $4 \cdot 10^{6} / \mathrm{mL}$, and their volume per vial $-200 \mu \mathrm{L}$. At cryopreservation the aggregates, formed in one well during short-term cultivation of initial NCs, were placed in cryocontainers. A day later frozen to $-80^{\circ} \mathrm{C}$ NCs were placed in liquid nitrogen. Thawing of cells was performed in a water bath at $+40^{\circ} \mathrm{C}$. After thawing for washing from DMSO a 10 -fold volume of DMEM/F12 medium was added to all samples with the cells and then NCs suspensions were centrifuged at $100 \mathrm{x} g$ for 3 minutes, and samples with aggregates were subjected to mild centrifugation with manual centrifuge at $100 \mathrm{rpm}$ for 5 minutes. The supernatant was removed, and the pellet of suspensions and NCs aggregates was suspended in $50 \mathrm{~mL}$ DMEM/F12 and used for transplantation. To assess the functional activity of NCs, native and cryopreserved aggregates, formed in one well were cultured in DMEM/F12 medium supplemented with $10 \%$ ARS.

For immunofluorescence (IF) studies cell cultures were fixed for 20 min at room temperature in $4 \%$ paraformaldehyde. Fixed cells were permeabilized in $100 \%$ ethanol, washed in phosphate buffer saline (PBS) and incubated for 60 min at room temperature in $5 \%$ solution of normal goat serum in PBS with $0.1 \%$ Triton X-100. The cells were then incubated overnight at $+4{ }^{\circ} \mathrm{C}$ with primary antibodies in $1 \%$ normal goat serum in PBS with $0.1 \%$ Triton X-100. The cells were then washed in PBS and incubated with secondary antibodies in a dilution of $1 \%$ normal goat serum on PBS with $0.1 \%$ Triton X-100 for 30 min at room temperature in the dark. As primary antibodies there were used mouse anti- $\beta$-tubulin III (Sigma, USA), mouse anti-GFAP (Abcam, UK), mouse anti-nestin ( $A b$ cam, UK) and rabbit anti-vimentin (Abcam, UK) antibodies. As secondary antibodies we used Chromeo 546 goat anti-mouse and Chromeo 488 goat anti-rabbit (Abcam, UK). The cell nuclei were stained with Hoechst 33342 (Sigma, USA).

The traumatic spinal cord injury was modeled on 6-8-month-old outbred white male rats weighing 300-400 g. The animals were not fed a day before operation. Anesthesia was performed by intramuscular injection of $1 \mathrm{~mL}$ mixture consisting of $0.18 \mathrm{~mL} 2 \%$ xylazine, $0.36 \mathrm{~mL} 10 \%$ ketamine and $0.46 \mathrm{~mL} 0.5 \%$ novocaine solution. Operations was carried out in sterile conditions. The injury was formed by dissection of the right spinal cord segment of about $2 \mathrm{~mm}$ length at the level of T10 thoracic vertebra [10]. After that, the spinal cord were isolated by subcutaneous adipose tissue. NCs transplantation was performed after muscles suturing in the spinal cord injury zone.

Registration of hind limb motor activity was performed after 1, 3, 14, 30,60 and 180 days after surgery using a modified method of movement analysis in open field test Basso [11] (Table. 1).

To prepare alginate hydrogel, $13 \%$ sodium alginate solution in saline with $25 \mathrm{mM}$ HEPES ( $\mathrm{pH}$ 7.2) was used. Sodium alginate was dissolved in a water bath at a temperature of $100{ }^{\circ} \mathrm{C}$. All preparations were carried out under sterile box conditions. Solutions were previously sterilized by filtration through a 0.22 micron filter (Millipore, USA).

The study was performed on 50 rats, 5 of which died after surgery. All experimental animals were divided into 5 groups: two control and three experimental (Fig. 1).

Immediately after surgery the animals from control group 1 were administered with $100 \mu \mathrm{L} \mathrm{DMEM/F12} \mathrm{medium} \mathrm{in} \mathrm{the} \mathrm{area} \mathrm{of} \mathrm{the} \mathrm{spinal} \mathrm{cord}$ defect, the animals from control group 2 were administered with $50 \mu \mathrm{L}$ of $13 \%$ alginate gel premixed with $50 \mu \mathrm{L}$ DMEM/F12 medium. The animals of the first experimental group were administered $4 \cdot 10^{6}$ thawed NCs suspension in $50 \mu \mathrm{L}$ DMEM/F12 medium; animals of the second experimental group $-4 \cdot 10^{6}$ thawed NCs suspension in $50 \mu \mathrm{L}$ DMEM/F12 medium mixed with $50 \mu \mathrm{L} 13 \%$ alginate gel. The animals of the third experimental group were injected with $50 \mu \mathrm{L} 13 \%$ alginate gel mixed with $50 \mu \mathrm{L}$ suspension of thawed NCs aggregates formed as a result of culture $4 \cdot 10^{6}$ cells. For injection the $100 \mu \mathrm{L}$ syringe (Hamilton, USA) with a $0.5 \mathrm{~mm}$ diameter needle was used.

\section{DISORDERS OF PHYSICAL ACTIVITY *}

\section{No observable hind limb movement}

Slight mobility of one limb, the other is in tone

Slight mobility of both limbs

Restricted mobility of one limb, the other weak

Restricted mobility of one limb, drawing of another

Restricted mobility of one limb, the other does not rely

Moderate mobility of one limb, the other relies weakly

Extensive mobility of one limb, poor mobility of the other

Extensive mobility of one limb, limited mobility of the other

Extensive mobility of both limbs

Full recovery of mobility
INDEX OF DISORDERS
Table 1. Scale of hind limbs motor function disorders in rats with spinal cord injury (modified method Basso [11]).

Notes: "slight mobility» - poor mobility of one joint; « restricted mobility» - limited mobility of one or two joints; " moderate mobility» limited mobility of three joints; "extensive mobility" - the extensive mobility of three joints or extensive mobility of two joints and limited mobility of one joint. 


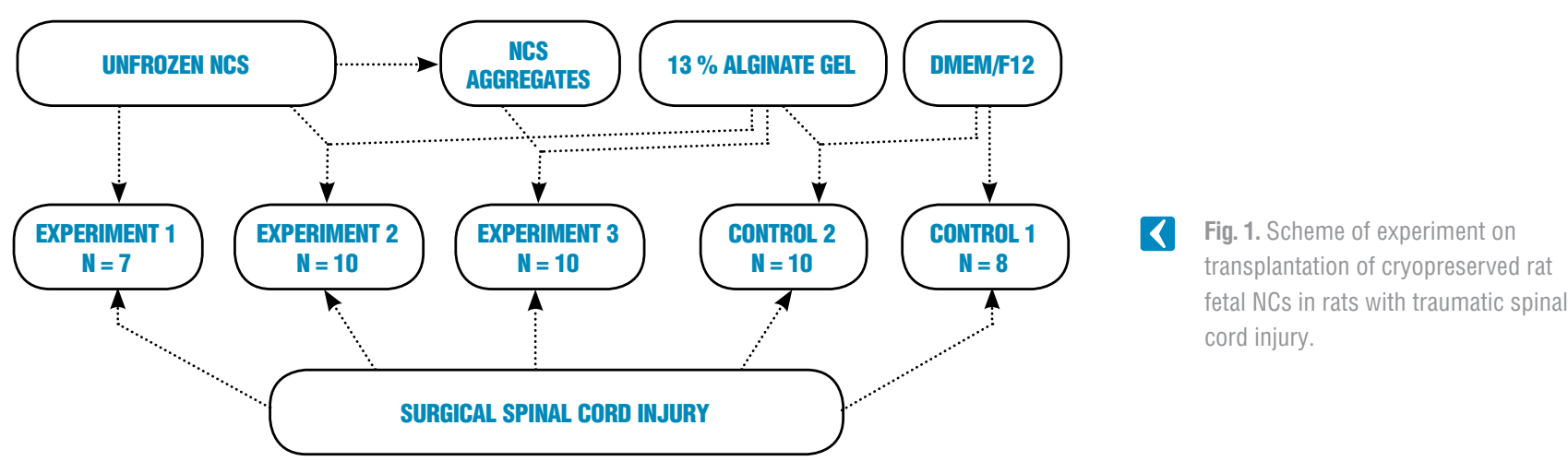

Fig. 2. Photomicrographs of aggregates formed during cultivation of purified NCs suspensions (A) or contaminated with erythrocytes (B). Light microscopy, scale bar A - $100 \mu \mathrm{m}, \mathrm{B}-50 \mu \mathrm{m}$.
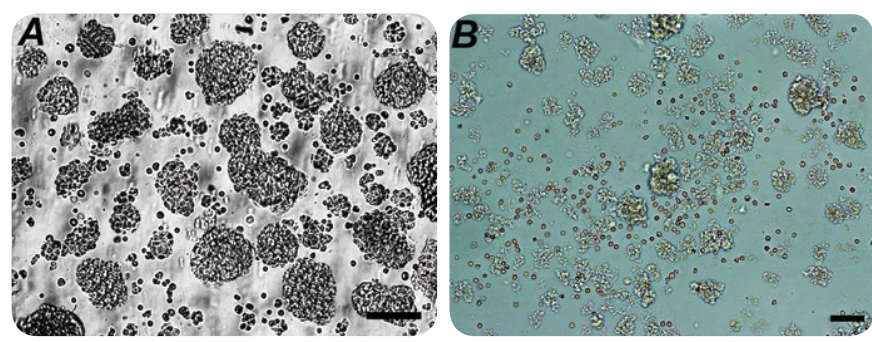

Histological examination of the spinal cord tissue was performed after fixation in $10 \%$ neutral formalin. Serial 6-8 $\mu \mathrm{m}$ sections were stained with hematoxylin and eosin. For photomicrography of cultures and histological preparations a microscope Axio Observer ZI (Carl Zeiss, Germany) was used.

Statistical analysis of the results was performed using Statistica v. 6.0 software (StatSoft, USA). For comparing of groups the Student's t-test was used. Results were considered significant when $p<0.05$.

\section{RESULTS AND DISCUSSION}

In the experiments we used isolated NCs suspension with an average viability $44.5 \%$. Short-term culturing of these cells at the presence of $10 \%$ ARS without mitogens resulted in the formation of multicellular aggregates (Fig. 2, A).

The aggregates were mainly formed by viable cells because the viability of aggregated cells was an average of $85.4 \%$. The experiments also showed that erythrocytes, which sometimes contaminated NCs suspension, were not included in the aggregates (Fig. 2, B).

During cultivation aggregates attached to the substrate (Fig. 3, A), after that, like in neurospheres, there was observed advancing forming of long $\beta$-tubulin III positive processes (Fig. 3, B), along which undifferentiated cells migrated (Fig. 4), forming after differentiation a monolayer composed of glial cells (Fig. 5) and neurons (Fig. 6).

When the area of the monolayer reached $70 \%$ confluency, first there appeared $\beta$-tubulin III positive neuroblasts-like cells (Fig. 7) and then colonies of undifferentiated nestin- or vimentin-positive cells (Fig. 8).

The obtained data indicate that in aggregates congregate viable stem/ progenitor and low differentiated cells, which are more resistant to the damage during isolation procedure compared to differentiated cells due to a simpler morphology and weaker intercellular junctions. Mature differentiated NCs during isolation apparently get damaged and die.

Thus, the formation of multicellular aggregates allows to carry out a selection of viable low differentiated and undifferentiated (stem/progenitor) NCs, solving the problem of standardization and unification before their use.

Cryopreserved aggregates after thawing and removal of DMSO maintained their integrity, morphology and size (Fig. 9).
Fig. 3. Photomicrographs of attached NCs aggregates (A). Cells from aggregates form $\beta$-tubulin III positive processes (green), IF staining. A - light microscopy, scale bar - $200 \mu \mathrm{m}$; B - luminescence microscopy, scale bar $-50 \mu \mathrm{m}$.
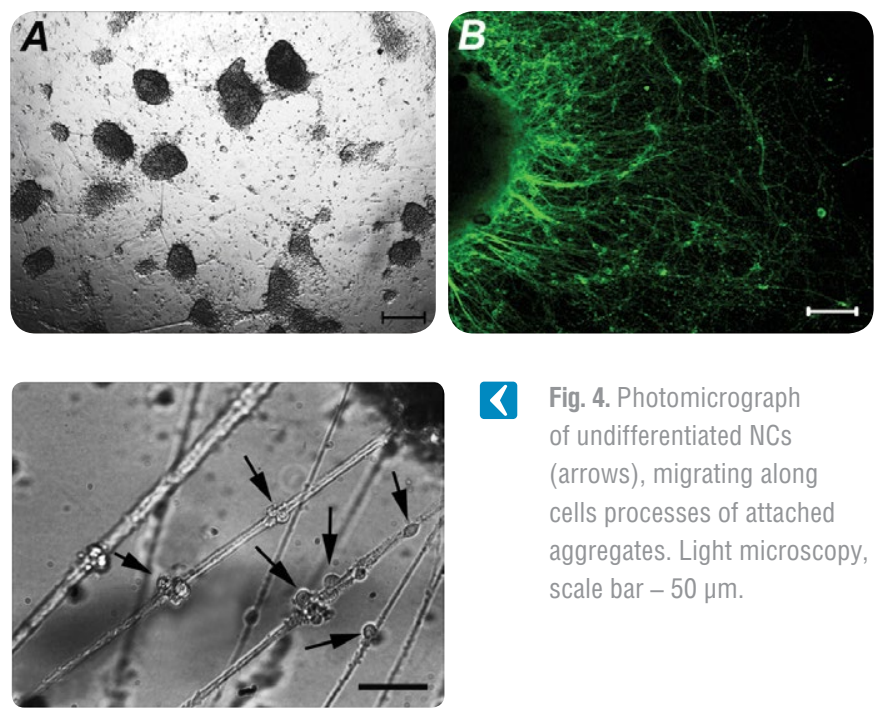

Fig. 4. Photomicrograph of undifferentiated NCs (arrows), migrating along cells processes of attached aggregates. Light microscopy, scale bar $-50 \mu \mathrm{m}$

They also retained the ability to attach to the substrate. After 3 days of cultivation more than $70 \%$ cryopreserved aggregates attached, then there was observed advancing formation of long $\beta$-tubulin III positive processes by NCs (Fig. 10, A), by which undifferentiated cells migrated (Fig. 10, B).

During cultivation cell processes of aggregates formed a network, and some of them merged together (Fig. 11).

Thus, high cryostability and the ability of NCs in the aggregates in vitro to form processes, along which migrate undifferentiated cells, served as a basis to consider promising their transplantation with the aim of restoring damaged nervous tissue of the spinal cord in rats.

To fix the transplanted NCs in spinal cord injury zone we used alginate - a linear anionic polysaccharide, which at the presence of divalent cations forms reticular gel [12]. As a biocompatible hydrogel, alginate is widely used to encapsulate cells and sections with the aim of immunoisolation [13-15]. In this case the alginate matrix is permeable to nutrients, oxygen, carbon dioxide, metabolic products and biologically active substances, which may be secreted by encapsulated cells. In addition, alginate increases the rate of axons and erythrocytes growth in the injured spinal cord $[16,17]$. It has also been demonstrated that transplanted neural stem cells (NSCs), encapsulated in alginate, can survive, differentiate, integrate and migrate in the recipient spinal cord tissue $[18,19]$.

One day after spinal cord injury there was observed a hind limb paralysis with decreasing sensitivity in all animals. The caudal part of the body was motionless. In this case muscle hypotonia was strongly pronounced. The hind limbs respond on the tactile and nociceptive stimuli was not observed. On the day 3 after NCs transplantation some 
Fig. 5. Photomicrographs of the monolayer formed by NCs of attached aggregates; IF staining for astrocyte marker GFAP (green) A - light microscopy; B - luminescence microscopy. Scale bar - $50 \mu \mathrm{m}$.
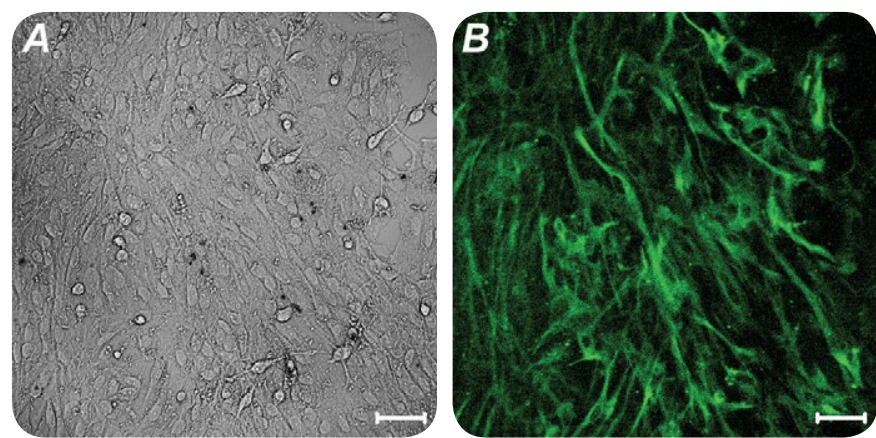

Fig. 6. Photomicrographs of NCs monolayer from attached aggregates; IF staining for neuronal marker $\beta$-tubulin III (green). A - light microscopy; B - luminescence microscopy. Scale bar $-50 \mu \mathrm{m}$
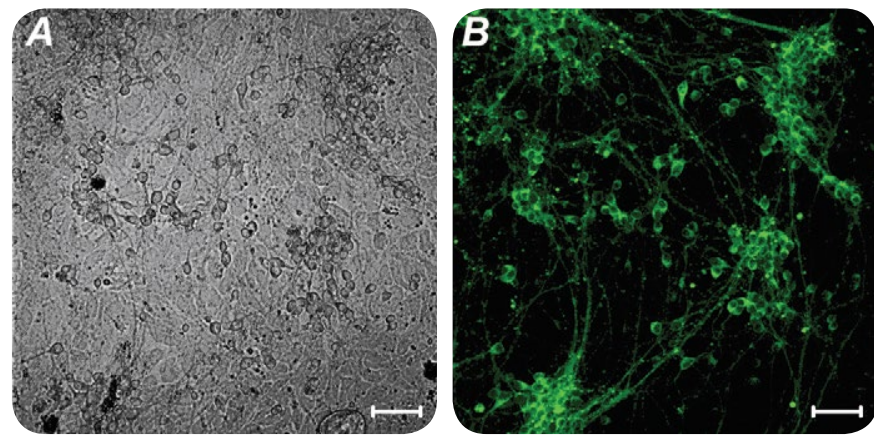

Fig. 7. Photomicrographs of neuroblast-like cells formed on the $6^{\text {th }}$ day of NCs aggregates culture; IF staining for $\beta$-tubulin III. A - light microscopy; B - luminescence microscopy. Scale bar - $50 \mu \mathrm{m}$.
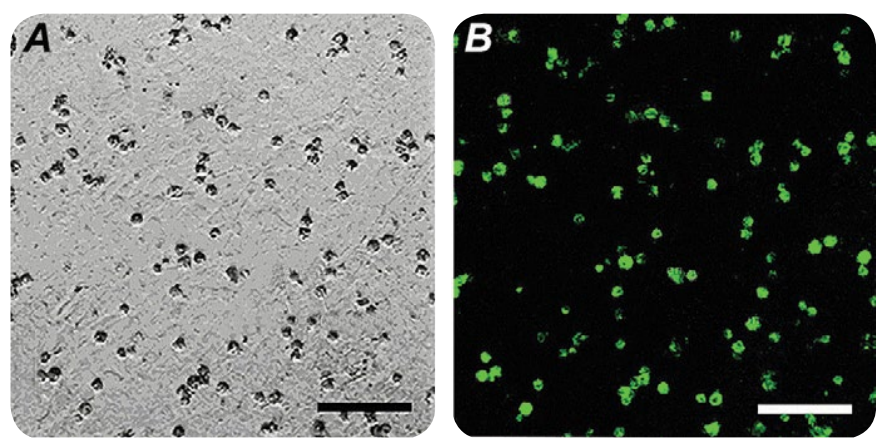

animals showed an increase in muscle tonus of the hind limbs. By the $14^{\text {th }}$ day the positive recovery dynamics of hind limbs motor activity was observed in animals of all treatment groups. Movement index in this case varied between 3.6-4.5 units (Table. 2) and was characterized by slight movements in one or two joints of the left limb and the complete absence of movement or weak movements of a joint of the right limb without pain sensitivity.

On $30^{\text {th }}$ day there was observed positive dynamics of hindlimb movements improving in animals of all treatment groups compared to $14^{\text {th }}$ day. In this case movement index increased to 4.4-5.2 units (Table. 2).

On $60^{\text {th }}$ day there was a significant increase in the index of hindlimb movements in the second and third experimental groups compared to the control groups. At that movement index in the experimental group 2 increased to 6.2, while in experimental group 3 - to 6.8 (Table. 2), which was characterized by a moderate mobility of the three joints of one leg and one joint of the other one.
Fig. 8. Photomicrographs of IF staining of NCs colonies (10 days of aggregates cultivation) for nestin (red) and vimentin (green); the nuclei are stained with Hoechst 33342 (cyan).

A - light microscopy

B-D - luminescence microscopy. Scale bar - $50 \mu \mathrm{m}$
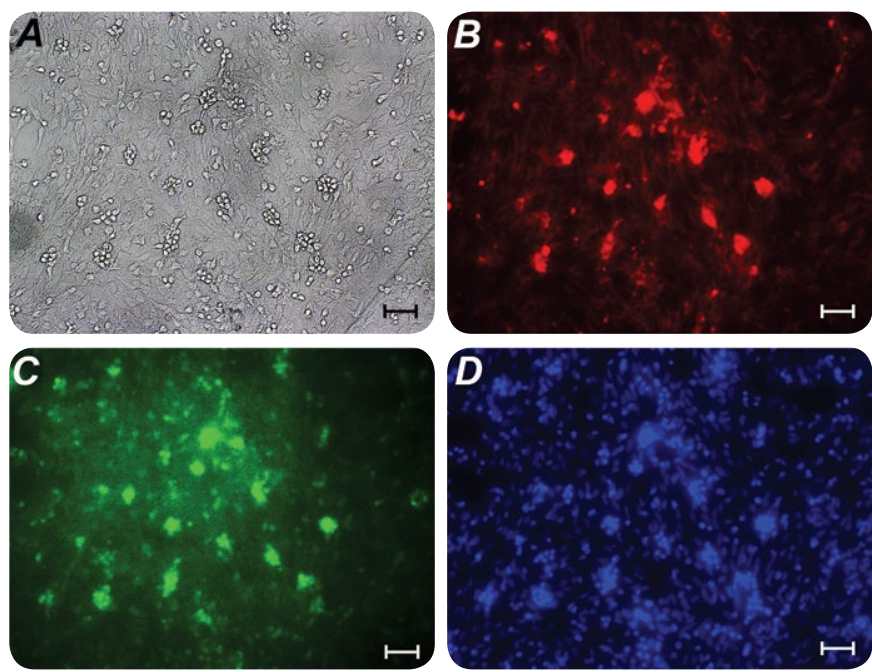

$\nabla$

Fig. 9. Photomicrograph of cryopreserved NCs aggregates after removal of DMSO. Scale bar - $100 \mu \mathrm{m}$.

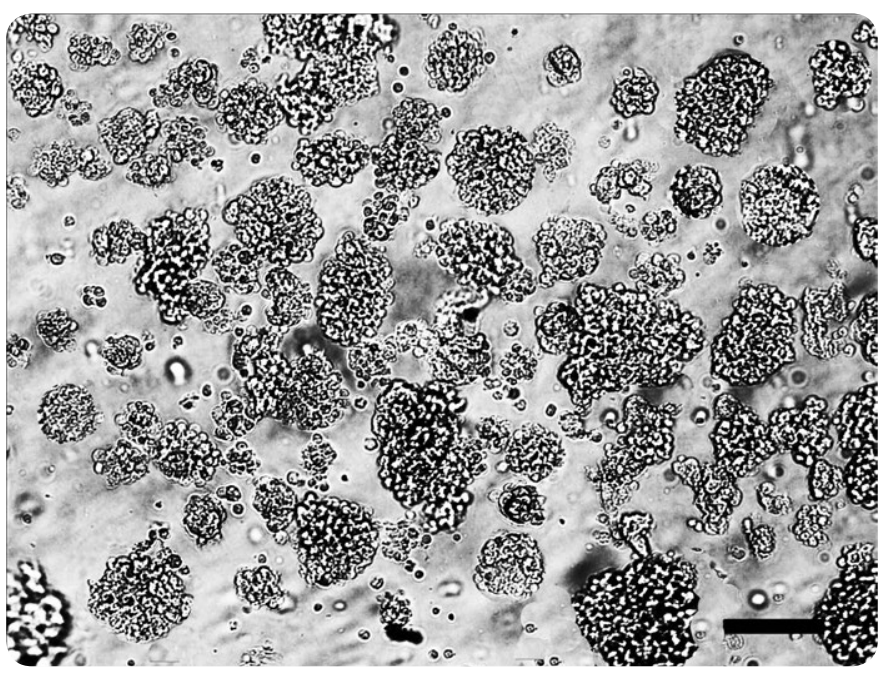

$\nabla$

Fig. 10. Photomicrographs of IF staining of $\beta$-tubulin III positive processes (green) formed during cultivation of the attached cryopreserved NCs aggregates; undifferentiated cells (arrows) migrate along processes. A - luminescence microscopy, scale bar - $100 \mu \mathrm{m}$;

B - light microscopy, scale bar $-20 \mu \mathrm{m}$.
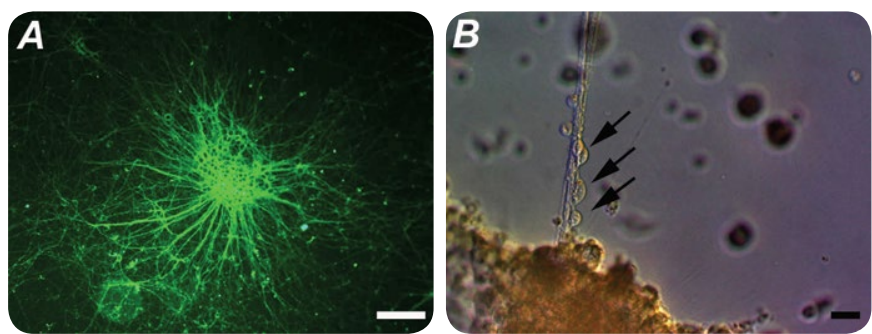


\begin{tabular}{|c|c|c|c|c|c|}
\hline \multirow{2}{*}{$\begin{array}{l}\text { TIME AFTER } \\
\text { SURGERY }\end{array}$} & \multicolumn{5}{|c|}{ INDEX OF THE HIND LIMB MOVEMENT } \\
\hline & $\begin{array}{c}\text { CONTROL } 1 \\
(\mathrm{~N}=8)\end{array}$ & $\begin{array}{c}\text { CONTROL } 2 \\
(\mathrm{~N}=10)\end{array}$ & $\begin{array}{l}\text { EXPERIMENT } 1 \\
(\mathrm{~N}=7)\end{array}$ & $\begin{array}{c}\text { EXPERIMENT } 2 \\
(\mathrm{~N}=10)\end{array}$ & $\begin{array}{l}\text { EXPERIMENT } 3 \\
(\mathrm{~N}=10)\end{array}$ \\
\hline 1 day & $0.2 \pm 0.2$ & $0.7 \pm 0.4$ & $0.7 \pm 0.5$ & $0.8 \pm 0.7$ & $0.7 \pm 0.6$ \\
\hline 3 days & $0.7 \pm 0.3$ & $1.0 \pm 0.01$ & $0.8 \pm 0.4$ & $0.8 \pm 0.5$ & $0.9 \pm 0.5$ \\
\hline 14 days & $4.3 \pm 0.5$ & $4.0 \pm 0.5$ & $3.6 \pm 0.5$ & $3.8 \pm 0.8$ & $4.5 \pm 0.9$ \\
\hline 30 days & $4.6 \pm 0.6$ & $4.4 \pm 0.4$ & $5.0 \pm 0.4$ & $4.4 \pm 0.7$ & $5.2 \pm 0.6$ \\
\hline 60 days & $5.0 \pm 0.5$ & $4.9 \pm 0.5$ & $5.2 \pm 0.4$ & $6.2 \pm 0.4^{*+}$ & $6.8 \pm 0.5^{*+}$ \\
\hline 180 days & $5.2 \pm 0.5$ & $5.0 \pm 0.1$ & $6.0 \pm 0.9$ & $6.4 \pm 0.7^{*+}$ & $7.8 \pm 0.6^{\star+\#}$ \\
\hline
\end{tabular}

Table. 2. Dynamics of hind limbs motor function recovery in rats after spinal cord injury.

Notes: control 1 - without transplantation; control 2 - transplantation of the alginate solution; experiment 1 - transplantation of NCs suspension; experiment 2 - transplantation of NCs suspension in the alginate solution; experiment 3 - transplantation of NCS aggregates in the alginate solution. - the differences are significant in comparison with control $1, p<0.05$

+-the differences are significant in comparison with control 2, $p<0.05$ \# - the differences are significant in comparison with experiment 2, $p<0.05$
By 180 days of observation the index of locomotor activity in the $1^{\text {st }}$ and $2^{\text {nd }}$ control groups was 5.2 and 5.0 (Table. 2) respectively, which was characterized by a evident movement of one or two joints of one hind leg and minor movements of one joint of the other. The average movement index of the hind limbs of experimental group 1 (NCs suspension transplantation) practically did not change and was 6.0 , which is not significantly different from that of two control groups. This index was characterized by a moderate mobility of three joints of one leg and one joint of the other.

The average index of hind limb movement of experimental group 2 (transplantation of NCs suspension with alginate gel) increased to 6.8 by $180^{\text {th }}$ day of observation (Table. 2), which differed significantly from that of both control groups. At the same time there was an extensive mobility of all three joints of one limb and slight or moderate mobility of two joints of the other. In this case, sensitivity of the hind limbs restored, although the response to painful stimulation of the left (injured) side was delayed. The average index of hind limb movement of experimental group 3 (transplantation of thawed NCs aggregates with alginate gel) increased to 7.7 to $180^{\text {th }}$ day (Table. 2), which is also significantly higher than the control group. At the same time there was an extensive mobility of all three joints of one limb and the limited mobility of two joints of the other. The sensitivity of the hind limbs, and their reaction to pain stimulation restored in this case.

In 120 days after the operation some animals of experimental and control groups were euthanized by decapitation. Spinal cord fragments were extracted and morphological analysis of their cuts was performed. As it can be seen from Fig. 12, the nerve tissue structure, formed in the area of damage, differed among different experimental groups of animals. Wherein the most ordered nervous tissue structures in the damaged area formed after transplantation of cryopreserved NCs aggregates together with alginate gel (Fig. 12).
Fig. 11. Photomicrograph of attached NCs aggregates; cells with long processes form the network. Light microscopy, scale bar $-100 \mu \mathrm{m}$.

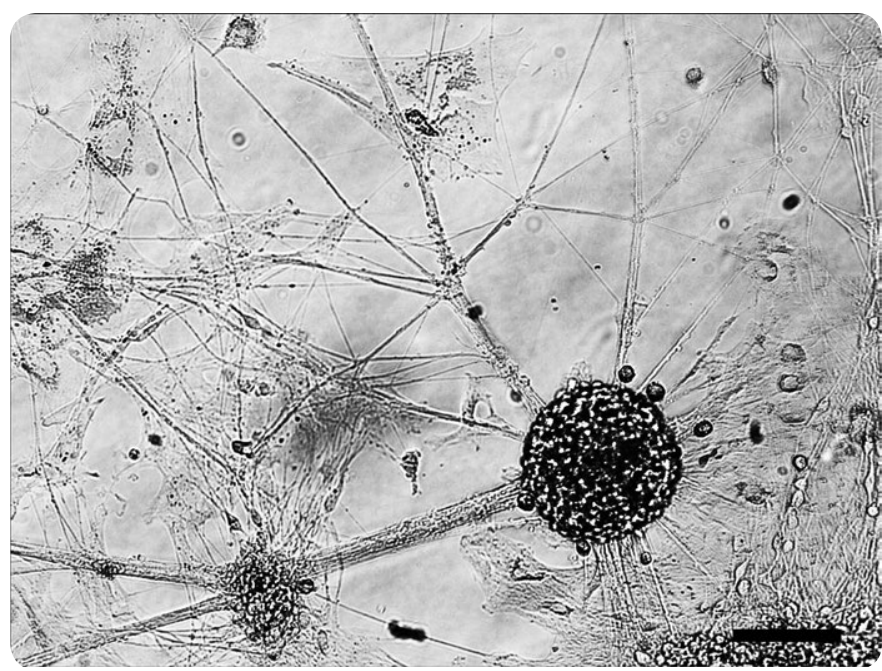

Thus, the experiments demonstrated that the administration of alginate gel hardly had a positive effect on the recovery of animals motor activity and the process of formation of nerve tissue in the injury zone. When administered NCs suspension, starting from 60 days, there was a trend towards improved locomotor activity of animals compared to controls. However, it also wasn't observed a marked positive effect after injection of NCs suspension on the neural tissue formation in the damaged area.
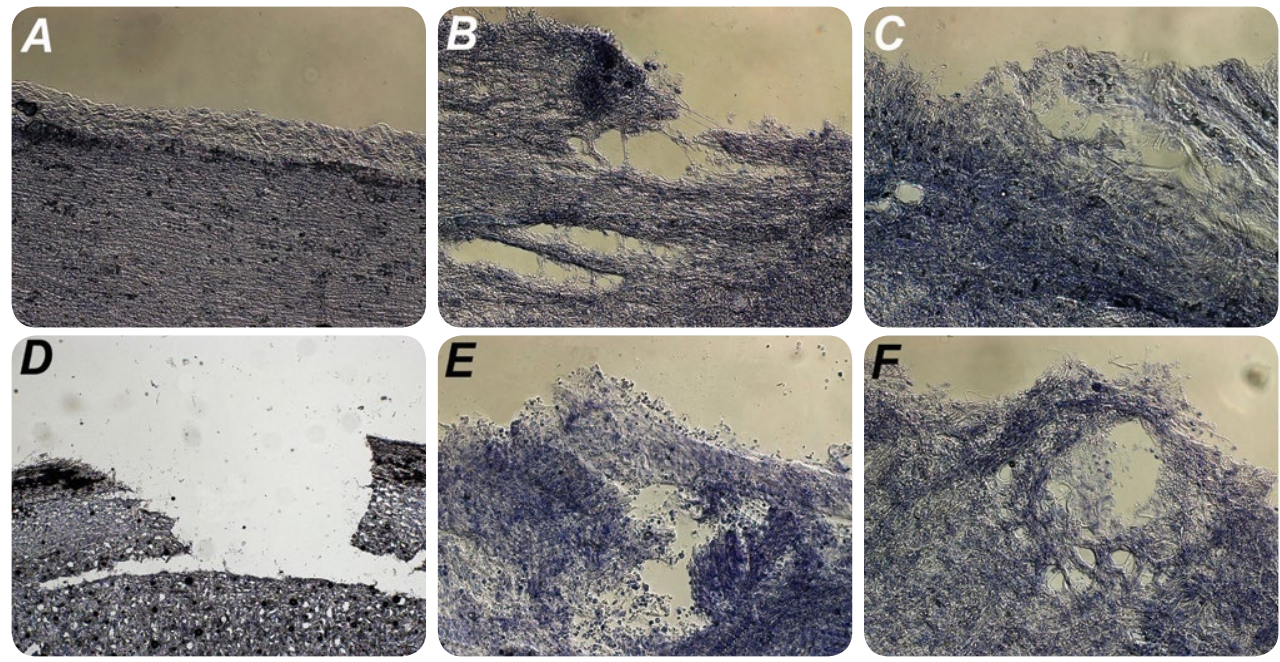

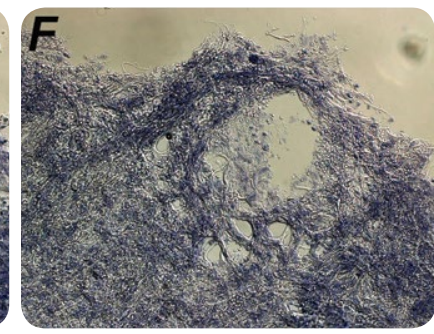

Fig. 12. Photomicrographs of spinal cord histological sections: norm (A); after traumatic injury (D); experimental group 120 days after transplantation of the alginate gel with cryopreserved NCs in aggregates (B), alginate gel with cryopreserved NCs in suspension (C), alginate gel alone (D) and cryopreserved NCs in suspension (F). Light microscopy. 
Transplantation of NCs suspension or multicellular aggregates, mixed with alginate gel, in spinal cord injury area, significantly improved recovery of locomotor activity of animals starting with 60 days post-administration.

Wherein if used the alginate gel with NCs aggregates, it was observed an increase of the motor index of animals hindlimbs compared to animals, treated with alginate gel with NCs suspension. As well when used the alginate gel with NCs aggregates, the forming neural tissue was characterized by more ordered structure compared to animals treated with alginate gel with NCs suspension.

The lack of significant improvement of locomotor activity in experimental animals after the transplantation of NCs suspension can be explained by the fact that transplanted cells do not fix in a damaged zone, and therefore their effect is appeared minimally. The use of NCs mixed with alginate gel allows to fix the transplanted cells in the injury zone. Protection of cells against unfavorable environmental conditions in the zone of transplantation is achieved by encapsulating. Furthermore, alginate gel may replace lost extracellular matrix by isolated NCs, promoting the normalization of their survival and function.

Our researches have shown that transplantation of alginate gel with NCs aggregates leads to better recovery of locomotor activity in experimental animals, and promotes formation of better arranged tissue structures in the damaged area in comparison with transplantation of alginate gel with NCs suspension. These data suggest an important role of cellular microenvironment for the effective function of the transplanted NCs. It is known that cellular and extracellular microenvironment is very important for the normal activity of the transplanted cells (such as stem/progenitor or differentiated). Neural SCs cannot function without their microenvironment - stem cell niche. If «purified» NSCs suspension is transplanted into the damaged area, they will likely die or effect incorrectly, due to the lack of adequate microenvironment. Perhaps this explains the low clinical efficacy of transplantation of "purified» NSCs suspensions at the cell therapy for neurodegenerative diseases.

NSCs are not able to migrate to necessary direction without appropriate auxiliary cells. For example, during embryogenesis neural stem and progenitor cells migrate along the processes of radial glial cells. Therefore, to provide an effective recovery of the neural tissue, it is necessary to reconstruct the conditions of embryogenesis in the damaged area, in which it is possible to form not only the whole complex of different types of cells, required for restoration of the damaged neural tissue, but also the ways of their migration. To modeling such conditions, transplantation of neurospheres into the damaged area was previously used [19, 20]. But, as it was shown by our experiments, the aggregates, formed by NCs isolated heterogeneous suspensions, can also be used as these structures. In this case, unlike neurospheres, the NSCs microenvironment in aggregates (cellular and extracellular) is more similar to the microenvironment in vivo, which allows expecting more effective and adequate differentiation of NSCs into desired cell type.

In the experiments for transplantation we have used heterogeneous suspension of fetal brain cells consisting of stem, progenitor and differentiated NCs. The advantage of such suspension over purified stem or differentiated NCs is not only presence of neural stem/progenitor cells, but also cells that make up their niche, which gives hope for more effective function of the transplanted stem cells in the injured spinal cord. The process of forming aggregates, in our opinion, is just accompanied by reconstruction of the microenvironment, similar to neural tissue in vivo, enabling NSCs to survive and function more effectively not only in culture but also after transplantation.

It should also be noted that in addition to the replacement of dead neuronal cells, transplantation of NCs may also influence the regeneration of spinal cord injury by secreting neurotrophic factors [21-23], as well as the factors leading to the destruction of molecules that inhibit axon growth $[24,25]$. It was found that NSCs, derived from various sources, secrete nerve growth factor (NGF), brain-derived neurotrophic factor (BDNF), glial derived neurotrophic factor (GDNF), and matrix metalloprotease-2, which destroy the chondroitin sulfate proteoglycan (a molecule that inhibits axonal growth) [21-26]. Thus, the transplanted neural stem/ progenitor cells may not only perform the function of tissue replacement, but also provide a therapeutic effect.

Studies have shown that transplantation of cryopreserved heterogeneous fetal NCs suspension into rats with spinal cord injury is effective if they are fixed in the damaged zone. Also, studies have shown prospects of multicellular aggregates usage for the transplantation, which being a three-dimensional micromodel of nervous tissue, increase the clinical efficacy of transplanted cells.

\section{CONCLUSION}

1. Rats with traumatic spinal cord injury since $60^{\text {th }}$ day after local transplantation of heterogeneous suspension of cryopreserved rat neural fetal cells in alginate gel, show the positive dynamics of motor function recovery.

2. Cryopreserved aggregates of neural fetal cells have higher therapeutic potential for spinal cord injury treatment in rats compared to neural cells suspension by improving the structure of forming nervous tissue and significantly increasing the rate of hind limb mobility recovery after 180 days.

\section{REFERENCES}

1. Sukach AN, Grischenko VI. Kletochnaya terapiya neyrodegenerativnykh bolezney: istochniki kletok i strategiya ikh primeneniya [Cell therapy of neurodegenerative diseases: cell sources and strategy for their application]. Uspekhi sovremennoy biologii - Biology Bulletin Reviews. 2007; 127(1): 25-33 [in Russian].

2. Emmerta MY, Hitchcock RW, Hoerstrupa SP. Cell therapy, 3D culture systems and tissue engineering for cardiac regeneration. Advanced Drug Delivery Reviews. 2014 69-70: 254-69.

3. Stabenfeldt SE, Munglani G, Garcia AJ, et al. Biomimetic Microenvironment Modulates Neural Stem Cell Survival, Migration, and Differentiation. Tissue engineering: Part A. 2010; 16(12): 3747- 58

4. Xu CJ, Wang JL, Jin WL. The Neural Stem Cell Microenvironment: Focusing on Axon Guidance Molecules and Myelin-Associated Factors. Journal of Molecular Neuroscience. 2015; 56(4,3): 887-97

5. Sukach AN. Kharakteristika embrional'nykh nervnykh kletok cheloveka, poluchennykh nefermentativnym sposobom [Characteristic of human embryonic neuronal cells obtained not enzymatically]. Tsitologiya - Cytology. 2005; 47(3): 207-13 [in Russian].

6. Sukach AN, Lyashenko TD. Rol' formirovaniya agregatov v protsesse vyzhivaniya izolirovannykh nervnykh kletok novorozhdennykh krys posle kriokonservirovaniya [The role of the formation of aggregates in the process of survival of isolated nerve cells of newborn rats after cryopreservation]. Problemy kriobiologii - Problems of Cryobiology. 2011; 21(4): 395-405 [in Russian].

7. Lyashenko TD, Shevchenko MV. Svoystva izolirovannykh kletok nervnoy tkani novorozhdennykh krys v kul'ture [Properties of the isolated cells from nervous tissue of newborn rat in the culture]. Biotechnologia Acta. 2013; 6(3): 63-8 [in Russian]. 
8. Petrenko $A Y u$, Sukach AN. Isolation of intact mitochondria and hepatocytes using vibration. Analytical Biochem. 1991; 194(2): $326-29$.

9. Sukach AN, Shevchenko MV, Liashenko TD. Comparative study of influence on fetal bovine serum and serum of adult rat on cultivation of newborn rat neural cells. Biopolymers and Cell. 2014; 30(5): 394-400.

10. Woerly S, Doan VD, Evans-Martin F, et al. Spinal cord reconstruction using NeuroGelTM implants and functional recovery after chronic injury. J. of Neurosciensce Res. 2001; 66: 1187-97.

11. Basso DM, Beatie MS, Bresnahan JC. Sensitive and reliable locomotor rating scale for open field testing in rats. Journal of neurotrauma. 1995; 12(1): 1-21.

12. Leea KY, Mooneya DJ. Alginate: Properties and biomedical applications. Progress in Polymer Science. 2012; 37(1): 106-26.

13. Lim F, Sun AM. Microencapsulated islets as bioartificial endocrine pancreas. F. Lim Science. 1980; 210(4472): 908-10.

14. Goren A, Dahan N, Goren E, et al. Encapsulated human mesenchymal stem cells: a unique hypoimmunogenic platform for long-term cellular therapy. FASEB J. 2010; 24(1): 22-31.

15. Gimi B, Nemani KV. Advances in alginate gel microencapsulation of therapeutic cells. Crit Rev Biomed Eng. 2013; 41(6): 469-81.

16. Matyash $M$, Despang F, Mandal $R$, et al. Novel soft alginate hydrogel strongly supports neurite growth and protects neurons against oxidative stress. Tissue Engineering. Part A. 2012; 18(1-2): 55-66

17. Suzuki K, Suzuki Y, Ohnishi K, et al. Regeneration of transected spinal cord in young adult rats using freeze-dried alginate gel. NeuroReport. 1999; 10(14): 2891-94.

18. Prang $P$, Muller $R$, Eljaouhari $A$, et al. The promotion of oriented axonal regrowth in the injured spinal cord by alginate-based anisotropic capillary hydrogels. Biomaterials. 2006; 27(19): 3560-69.

19. Wu S, Suzuki Y, Kitada M, et al. Migration, integration, and differentiation of hippocampus-derived neurosphere cells after transplantation into injured rat spinal cord. Neuroscience Letters. 2001; 312(3): 173-76.

20. Nori S, Okada $Y$, Yasuda A, et al. Grafted human-induced pluripotent stem-cell-derived neurospheres promote motor functional recovery after spinal cord injury in mice. Proc Natl Acad Sci USA. 2011; 108(40): 16825-830.

21. Llado J, Haenggeli C, Maragakis NJ, et al. Neural stem cells protect against glutamate-induced excitotoxicity and promote survival of injured motor neurons through the secretion of neurotrophic factors. J. Mol Cell Neurosci. 2004; 27(3): 322-31.

22. $L u P$, Jones $L L$, Snyder $E Y$, et al. Neural stem cells constitutively secrete neurotrophic factors and promote extensive host axonal growth after spinal cord injury. Exp Neurol. 2003; 81(2): 115-29.

23. Cao $Q$, He $Q$, Wang $Y$, et al. Transplantation of ciliary neurotrophic factor-expressing adult oligodendrocyte precursor cells promotes remyelination and functional recovery after spinal cord injury. J Neurosci. 2010; 30(8): 2989-3001.

24. Heine W, Conant $K$, Griffin JW, et al. Transplanted neural stem cells promote axonal regeneration through chronically denervated peripheral nerves. Exp Neurol. 2004; 189(2): 231-40.

25. Liu H, Shubayev V. Matrix metalloproteinase-9 controls proliferation of NG2+ progenitor cells immediately after spinal cord injury. Exp Neurol. 2011; 231(2): 236-46.

26. Li X, Liu T, Song K, et al. Effect of neural stem cells on apoptosis of PC12 cells induced by serum deprivation. Biotechnol prog. 2007; 23(4): 952-57.

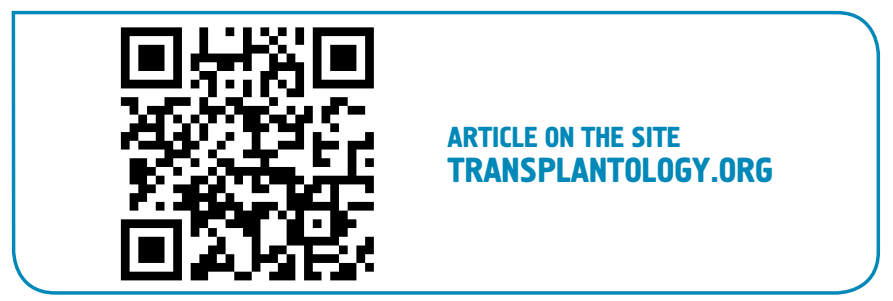

The authors indicate no potential conflicts of interest. 